\title{
NEW WAYS OF ANALYSING THE HISTORY OF VARIETIES OF ENGLISH - AN ACOUSTIC ANALYSIS OF EARLY POP MUSIC RECORDINGS FROM GHANA
}

\author{
SEBASTIAN SCHMIDT \\ Justus Liebig University, Giessen
}

\begin{abstract}
Focusing on English in Ghana, this paper explores some ways in which early popular music recordings might be used to reconstruct the phonology of colonial and post-colonial Englishes in a situation where other recordings are (mostly) absent.

While the history of standard and, to a certain degree, non-standard varieties of "Inner Circle Englishes" (Kachru 1986) has received linguistic attention, diachronic investigations of Outer Circle varieties are still the exception. For the most part, descriptions of the history of post-colonial Englishes are restricted to sociohistorical outlines from a macro-sociolinguistic perspective with little if any reference to the linguistic structure of earlier stages of the varieties. One main reason for this lack of diachronic studies is the limited availability of authentic historical data. In contrast to spoken material, written sources are more readily available, since early travel accounts, diaries or memoirs of missionaries, traders and administrators often contain quotes and at times there are even documents produced by speakers of colonial Englishes themselves (cf. the diary of Antera Duke, a late 18th century Nigerian slave trader; Behrendt et al. 2010). Such material provides insights into the morphology, syntax and the lexicon of earlier stages of varieties of English (cf. Hickey 2010), but it is inadequate for the reconstruction of phonological systems. Obtaining spoken material, which permits phonological investigation, is far more difficult, since there are comparatively few early recordings of Outer Circle Englishes. In such cases, popular music recordings can fill the gap.

I will present first results of an acoustic analysis of Ghanaian "Highlife" songs from the 1950s to 1960s. My results show that vowel subsystems in the 1950s and 1960s show a different kind of variation than in present-day Ghanaian English. Particularly the STRUT lexical set is realized as /a, o/ in the Highlife-corpus. Today, it is realized with three different vowels in Ghanaian English, /a, $\varepsilon$, J/ (Huber 2004: 849). A particular emphasis will also be on the way Praat (Boersma and Weenink 2011) can be used to analyze music recordings.
\end{abstract}

\section{Introduction}

The present study is concerned with the structural development of World Englishes. Focusing on English in Ghana, the former British Gold Coast colony, this paper explores ways in which early popular music recordings might be used to reconstruct the phonology of colonial and post-colonial Englishes in a situation where other recordings are (mostly) absent. The database consists of early 20th century music recordings from 
the former Gold Coast colony and the emerging independent post-colonial nation of Ghana. The recordings contain lyrics that can be regarded as authentic historical nearspoken data. This source as a linguistic database is made accessible, because recordings of colonial or early post-colonial Englishes are rare. In several pilot studies (cf. Huber \& Schmidt 2011a and 2011b, Schmidt 2011a) the potentials and methodological challenges of using early popular music lyrics for the analysis of earlier stages of Outer Circle (Kachru 1986) varieties of English have been explored.

For the present study, a pilot corpus of popular music lyrics from 1950s Gold Coast Colony and then, from 1957 onwards, post-independence Ghana has been compiled. The actual recordings and the transcribed lyrics have been subject to an auditory (Huber \& Schmidt 2011a) and an acoustic analysis (Schmidt 2012b). In both studies, the focus is on sound change and on the differences between RP and Ghanaian English (GhE). The motivation of the acoustic analysis is first of all to investigate if early music recordings can be used within the context of an acoustic study at all and secondly to what extent the results fit in with the findings generated by the auditory analysis. The present paper brings the two analyses together. It is structured into three major sections, 1.) background information on the data, 2.) a report on the methods and tools that were applied, and 3.) a discussion of the findings and an outlook.

\section{Background and Data}

Kreyer and Mukherjee (2007) worked quantitatively and qualitatively on the style of pop song lyrics in general. They also investigated vocabulary and lexicogrammatical routines. In order to do so, the authors compiled the Giessen-Bonn Corpus of Popular Music (GBoP). The GBoP consists of transcripts of popular music lyrics of various heterogenous genres, such as rock music and rap. Kreyer and Mukherjee's study is based on the GBoP and focuses on written language. They call for a systematic, corpus-based approach to popular music lyrics as linguistic data on all descriptive levels. The authors show that it is worthwhile working with popular music lyrics as a linguistic database. Furthermore, they suggest that a corpus-based approach to the study of the language in popular music should be preferred.

Miethaner (2005) uses the BLUR-corpus (Blues Lyrics collected at the University of Regensburg) to reconstruct earlier stages of African American English (AAE). By applying corpus linguistic methodology, $B L U R$ turns out to be an appropriate and valid representation of earlier AAE. Miethaner demonstrates that blues lyrics can be used to reconstruct the morphology, morphosyntax and syntax of earlier AAE.

Trudgill (1983) diachronically investigates English pop-singers' pronunciation. Among others, rhoticity serves as one linguistic variable. He observes a trend to sing in an Americanized way in the 1950s and 60s but this trend is weakened at the latest with the advent of punk-rock in the late 1970s in favour of a local English pronunciation. By comparing several records of The Beatles and The Rolling Stones from 1963 until 1969, Trudgill emphasizes the diachronic perspective of his study. As a result, the author shows the importance of linguistic models and of identity in the context of the language used in popular music. 
In this tradition, Brato and Jansen (2008) focus on both southern and northern English indie rock bands, such as The Arctic Monkeys and The Kooks. Conducting an auditory analysis of a selection of songs, they find that the bands they looked at are generally English in their pronunciation and even exhibit regional accent features, such as typically marked Sheffield English.

West African popular music lyrics have also been subject to linguistic analysis. Both Coester (1998) and Culver (2007 and 2008) show an interest in the language of the late Nigerian musician Fela Anikulapo Kuti. As Coester (1998) points out, Kuti's lyrics are characterized by an "intermingling of languages" (Coester 1998). The author shows that the language in Kuti's 1970s and 1980s lyrics alternates between Nigerian Pidgin (NigP), Standard English (StE) and Yoruba, sometimes even within a single song. These alternations are frequent and give distinction to Kuti's style and the genre Afro-Beat of which Kuti is regarded to be the founding-father.

The present study is a corpus-based, diachronic analysis of phonological details in early Ghanaian popular music. The selected lyrics stem from a genre called Highlife. Highlife is a form of dance-music of West African origin which was popular both with the white minority and the local population (Bender 1985 and 2007, Collins 1986 and 1989, Oti 2009).

The musicologist Collins has worked extensively on Highlife music (cf. Collins 1986 and 1989), which he considers an umbrella term for West African popular music that had its heyday around the time of Ghana's independence in 1957 (cf. Collins 1986 and 1989). According to Collins, Highlife is characterized by "fusion" on the levels of musical styles, cultures and languages (Collins 1989: 221). English and Pidgin lyrics represent only a fraction of Highlife songs which were recorded in a variety of languages. Some of the songs contain both local Ghanaian languages and English or Pidgin English. There are also Pidgin elements within otherwise StE-oriented songs. Hybridity in terms of stylistic and cultural diversity as well as language fusion are, from a linguistic point of view, the central characteristics of early West African popular music.

Crucial for the acoustic analysis is the recording situation: According to Collins (personal communication), the singer stood near or in front of the recording microphone. The band was placed behind him and thus further away from the microphone. The music was originally distributed on gramophone records. These were digitalized and stored as .wav-data. It was particularly paid attention not to alter the voice in any way. To sum up, the voice of the singers is generally 'in front of the music' so that the music can be treated as background noise when vocals are measured.

\section{Linguistic Context}

Ghanaian English is an Outer Circle variety of English (Kachru 1982, 1986), which was brought to the territory of modern Ghana through trading contacts and colonisation (Huber 1999, 2008). Huber and Schmidt (2011a) locate modern GhE between nativization and the endonormative stabilization stage in Schneider's evolutionary model (Schneider 2003, 2007). Currently, GhE is the "de facto official language" (Huber 2008: 72) in Ghana, because the status of English in Ghana is not specified in the constitution 
of the country. Nevertheless, GhE is spoken in most public domains such as schools, the media and in parliament. In contrast to local languages, it "has the advantage of ethnic neutrality" (Huber 2008: 73), which is an important aspect in a multi-ethnic and multilingual region.

Based on a structural investigation of GhE, as conducted by Huber (2008), "it should be kept in mind that on all descriptive levels, GhE is a system of tendencies rather than categorical differences from the British standard" (Huber 2008: 74). Especially in the public domain, the British standard has overt prestige. Ghanaian speakers of English often claim to sound RP, while in fact speakers often favour a distinct Ghanaian pronunciation to dissociate themselves from speakers of other West African varieties of English.

The present-day GhE vowel inventory is characterised by a reduction of the twelve RP monophthongs to the following seven: /i/, /e/, / / /, [a], [o], [o], [u] (Huber 2008: 75). Importantly, the RP central vowel $/ \Lambda$ / is not part of the GhE vowel system (Huber 2008: 76).

\section{Pilot Study I: Auditory Analysis}

The vowel quality of RP / $/$ (STRUT; Wells 1982 and 2010) varies considerably in present day Ghanaian English (cf. Huber 2008). This is why the standard lexical set STRUT was chosen as the variable for an auditive study of the pronunciation in early Ghanaian popular music lyrics (cf. Huber \& Schmidt 2011a). The STRUT vowel is here defined as the central monophthong lower than schwa (cf. Ladefoged 2006). Huber and Schmidt (2011a) compared the $/ \mathrm{N} /$ vowel sub-system in the corpus of early Highlife lyrics with Huber's (2008) report on contemporary GhE. The song lyrics were transcribed orthographically by Schmidt and proof-read by Huber and students from the University of Ghana. Word lists containing all RP STRUT words were extracted from the Highlife corpus. Then, both authors coded RP STRUT variants as follows:

open vowel $=\mathrm{a}$

half-open back vowel $=0$

closed back vowel $=\mathrm{u}$

undecided/between ' $a$ ' and 'o' = m

Depending on the actual realization, love would, for example, be coded as love_o, love_a or love_m. An inter-rater agreement of $97,2 \%$ was reached.

As expected, variation in the realisation of RP STRUT in the 1950s/1960s songs is clearly observable. The main variants, though, are $/ \mathrm{a} /$ and $/ \mathrm{o} / . / \varepsilon /$, a current $\mathrm{GhE}$ variant of RP STRUT, was not found in the Highlife corpus. Surprisingly, come was consistently realized as $/ \mathrm{k} v \mathrm{~m} /$ in the song "Apolonia" by The Builders Brigade Band. To date, not enough is known about the singer or the band to give a solid explanation, particularly, because love is realized throughout the song as /lav/. 


\section{Acoustic Analysis}

For the acoustic analysis, the transcriptions of the songs were transferred to PRAAT text grids as required for most PRAAT scripts (Lennes 2003). The selection of songs had to be revised, though. In the auditory analysis, even rather damaged recordings could be included, because, after some training, human coders could work well with them. However, when analysed with PRAAT (Boersma and Weenink 2011), the formants in these songs could not be measured to a satisfactory degree.

My text grids consist of three tiers, a 'line'-tier, a 'word'-tier and a 'vowel'-tier. All variants of RP STRUT are marked on tier 3, the vowel-tier. Due to the relatively small number of data-points this was done manually. A modified version of Lennes' (2003) script was used to measure the marked sections on the vowel-tier. The generated output was normalised using the NORM vowel-normalisation suite by Thomas and Kendall (2011). The Bark Difference Metric was chosen for normalisation, because this method works well with vowel sub-systems (Thomas and Kendall 2011). Figurel shows the plotted RP STRUT words in the selected songs. Z3-Z2 represents the front-back dimension, Z3-Z1 the height dimension in analogy to a standard vowel chart (cf. Ladefoged 2006). The STRUT words auditorily coded as 'a' by Huber and Schmidt (2011a) are plotted in red. They cluster in the lower half of the diagram whereas the 'o' words in blue gather in the upper part. Love coded as 'm' (green) falls in between. For current GhE, Huber (2008) shows that the open vowel /a/ and the half-open vowel /o/ are typical realisations of RP STRUT. The acoustic analysis confirms that RP $/ \Lambda /$ was already realized as $/ \mathrm{a} /$ and $/ \mathrm{s} /$ in $1950 \mathrm{~s} / 60 \mathrm{~s} \mathrm{GhE}$.

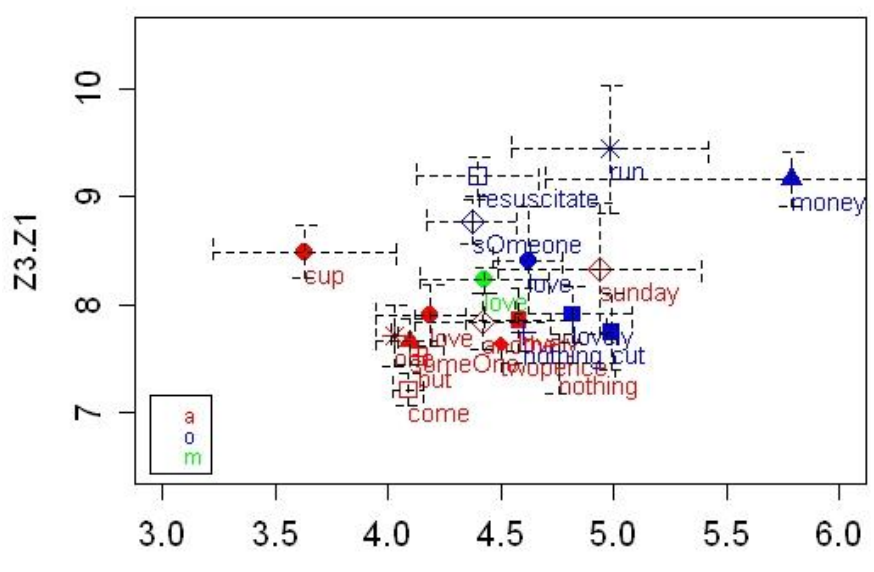

$Z 3 . Z 2$

Figure 1: Vowel plot of RP STRUT words in a selection of early Ghanaian Highlife songs. 
As the diagram shows, the acoustic pilot study confirms the findings from the auditory one (Huber and Schmidt 2011a). Apart from cup, all instances of RP STRUT in the Highlife corpus cluster towards the back-end of Z3-Z2. There is a tendency for words coded as 'o' to display a backer quality than tokens coded ' $a$ '. There is also a tendency towards a height divide between 'a'-tokens and 'o'-tokens with only Sunday as an outlier. Figure1 also confirms the correct application of the ' $m$ '-code, because the token love coded as ' $\mathrm{m}$ ' is located between most ' $\mathrm{a}$ ' and ' $\mathrm{o}$ ' tokens.

The results for RP STRUT words in the Highlife corpus encourage further acoustic analyses aiming at a complete representation of the vowel system of early Highlife songs.

In conclusion, the lyrics of early popular music recordings can be analysed acoustically. Furthermore, the present study also shows that the results from the auditory study correspond to a large extend with the acoustic analysis. Through the application of both methods we get a glimpse of the English spoken in Ghana in the $1950 \mathrm{~s} / 60 \mathrm{~s}$.

\section{Challenges}

Early popular music in its original form is stored on various analogue records. Visits to archives, for example to the African Music Archive (AMA), Mainz, Germany, and experience from field work show that much depends on the condition of the actual record. Record here - since we are talking of the 1950s/60s - basically means shellac gramophone records and vinyl records. Depending on the frequency of use, the technology used for playing the records and the conditions of the respective archives or storerooms, the records deteriorate. Deterioration is inevitable due to the material characteristics of shellac and vinyl. Loss of data quality and sometimes of whole collections of music has to be taken into consideration. Apart from the purely physical aspect mentioned above, it is a challenge to contextualize the data.

Although ethno-musicologist Coester is currently working on the biographies of early Highlife singers, not much is known in detail about them. From a sociolinguistic or sociophonetic perspective, it would be helpful to know more about the singers, their L1s, educational background and if they had lived or toured extensively abroad for longer periods of time, for instance in Nigeria or the USA. Basic information about the singers can often be retrieved from the labels on the records. For example, in the case of the song “Awirehow" by E.T. Mensah and His Tempo's Band, the vocalist is identified as Dan Acquaye. In the case of "The Tree and the Monkey", also by E.T. Mensah and His Tempos Band, Julie Okine is mentioned, who is so far the only female singer in the corpus of early Highlife recordings. Due to typical regional and ethnic affiliation, though, it can be inferred from the names with some certainty to which ethnic group in Ghana a person belongs. Okine, for instance, is a Ga name (Anderson, personal correspondence).

Another challenge is the acquisition of data. Highlife recordings are scattered over various archives all over the world. The Gramophone Library of the Ghana Broadcasting Corporation (GBC) in Accra for instance holds a vast collection of shellac records from the 1950 s and 1960s that is being digitalised. Recordings made by Decca West Africa 
are held at the British Library. For the purpose of linguistic analyses, digital recordings in high .wav quality are indispensable and so an extensive database needs to be compiled. Technical issues prove less challenging than legal issues in this respect. It is often not clear who the copyright owners are and if digital copies of the recordings can be made available for research purposes.

\section{Outlook}

In order to generate a vowel system of early Ghanaian Highlife pronunciation, the methodology outlined above has to be repeated for other lexical standard sets as well, especially those which exhibit different realizations in RP and GhE (Huber 2008: 74, 81). Some Highlife songs are performed in a more 'spoken' way (performed somewhat similarly to talking blues). In these songs, vowel length merging can also be analysed.

Turning to consonants, / $\mathrm{t}$ /-affrication is a variable worth investigating. It is described by Wells (1982) as "a common allophone of /t/ in a London accent [which] is a heavily

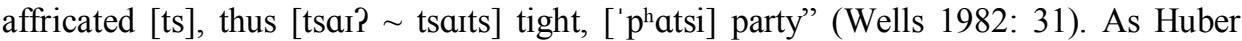
(2008) observes for GhE, /t/-affrication has currency there, because "in the Fante dialect of Akan, /t/ has two allophones: [t] before back vowels and affricated [ts] before front vowels. Speakers of the dialect sometimes transfer this allophony to English and, for example, pronounce the name Martin [matsin]" (Huber 2008: 84).

Although current GhE is described as non-rhotic (Huber 2008: 87), the pronunciation of post-vocalic $/ \mathrm{r}$ / is a feature of a number of singers. An analysis of rhoticity in the Highlife corpus could provide empirical evidence of this phenomenon. An hypothesis which needs to be tested is whether rhoticity can be attributed to an orientation towards American popular music (cf. Trudgill 1983).

In the long run, early popular music recordings from Ghana will be compared to recordings from other colonial or post-colonial contexts. Nigeria with its extensive heritage of Highlife and Afro-Beat is an obvious contender for comparative studies. The same is true for Sierra Leone where Calypso culture brought forth an extensive number of recordings containing English or Krio lyrics in the 1950s and 1960s.

The advantage for linguists, who are interested in diachronic perspectives of popular music is that there is an ongoing, though not unproblematic (Hassold 2005), recording tradition in West Africa. From this rich source we are currently compiling a comprehensive corpus of music lyrics.

\section{References}

Behrendt, Stephen D., A.J.H. Latham and David Northrup (2010): The Diary of Antera Duke, an Eighteenth-century African Slave Trader. Oxford: OUP.

Bender, Wolfgang. 1985. Sweet Mother - Moderne Afrikanische Musik. München: Trickster Verlag.

Bender, Wolfgang. 2007. Der Nigerianische Highlife. Musik und Kunst in der populären Kultur der 50er und 60er Jahre. Wuppertal: Peter Hammer Verlag. 
Boersma, Paul and David Weenink. 2011. Praat: Doing Phonetics by Computer. Version 5.2.44. [Computer Programme].

Brato, Thorsten \& Sandra Jansen. 2008. "'You used to gerri' in yer fishnets, now you only gerri' in yer nightdress': Regional and supraregional accents in English rock songs". Presented at The Thirteenth International Conference on Methods in Dialectology. Leeds, 04 August. http://www.thorsten-brato.de/en/conferencespresentations/. Accessed: 20 February 2012.

Coester, M. 1998. Language as a product of cultural contact. In: ntama Journal of African Music and Popular Culture. http://www.uni-hildesheim.de/ntama/. Accessed: 5. March 2012.

Collins, John. 1986. E.T. Mensah: King of Highlife. London: Off the Record Press.

Collins, John. 1989. "The early history of West African highlife music". Popular Music. Vol. 8, No. 3. 221-230.

Culver, Christopher. 2007. Fela's Nigerian English. http://www.christopherculver.com/linguistweblog/2007/10/felas-nigerian-english/.

Culver, Christopher. 2008. A linguistic approach to Fela Kuti's lyrics. http://www.christopherculver.com/linguistweblog/2008/01/a-linguistic-approach-tofela-kuti\%E2\%80\%99s-lyrics/. Accessed: 5. March 2012.

Hassold, Finn. 2005. Die Krise des Highlife - Zur Entwicklung der populären Musik in Ghana. München: GRIN.

Hickey, Raymond (Ed.) (2010): Varieties of English in Writing. The Written Word as Linguistic Evidence. Amsterdam: John Benjamins.

Huber, Magnus (2004): "Ghanaian English: Phonology." In Kortmann, Bernd and Edgar W. Schneider (Eds.): A Handbook of Varieties of English. A Multimedia Reference Tool. Volume 1: Phonology. Berlin: Mouton de Gruyter. 842-865.

Huber, Magnus. 2008. "Ghanaian English: phonology." In: Rajend Mesthrie (ed.). Varieties of English 4 - Africa, South and Southeast Asia. Berlin: Mouton de Gruyter. 67-92.

Huber, Magnus \& Sebastian Schmidt. 2011a. "New ways of analysing the history of varieties of English - Early Highlife recordings from Ghana". Presented at ISLE 2. Boston, 17-21 June 2011.

Huber, Magnus \& Sebastian Schmidt. 2011b. "Investigating the history of Pidgin English - Early Highlife Recordings from Ghana". Presented at The 2011 Summer Conference of the Society for Pidgin and Creole Linguistics. Accra, Ghana, 2-6 August 2011.

Kachru, Braj (ed.). 1982. The Other Tongue: English across cultures. Urbana: University of Illinois Press.

Kachru, Braj B. (1986): The Alchemy of English. The Spread, Functions, and Models of Non-Native Englishes. Chicago: The University of Illinois Press.

Kreyer, Rolf \& Joybrato Mukherjee. 2007. "The style of pop song lyrics: a corpuslinguistic pilot study". Anglia. 125 (1). 31-58.

Ladefoged, Peter. 2006. A course in Phonetics. Boston: Thomson.

Lennes, Mietta. 2003. collect_formant_data_from_files.praat. [Computer Script].

Source: http://www.helsinki.fi/ lennes/praatscripts/public/collect_formant_data_from_files.praat. Accessed: 5. March 2012. 
Oti, Sonny. 2009. Highlife Music in West Africa: Down Memory Lane. Lagos, Nigeria: Malthouse.

Schmidt, Sebastian. 2011. "Tracing the Lyrics - Early Highlife Recordings from Ghana as Linguistic Data and Cultural Artifacts". Presented at the GCSC-Workshop Korpus Kommunikation Kultur: Linguistik als Kulturwissenschaft. Gießen, 4. November 2011.

Schneider, Edgar W. 2007. Postcolonial English: Varieties Around the World. Cambridge: Cambridge University Press.

Schneider, Edgar W. 2003. "The dynamics of New Englishes: From identity construction to dialect birth". Language 79 (2), pp. 233-281.

Thomas, Erik R. and Tyler Kendall. 2007. NORM: The vowel normalization and plotting suite. [ Online Resource: http://ncslaap.lib.ncsu.edu/tools/norm/ ].

Trudgill, Peter. 1983. "Acts of conflicting Identity - The sociolinguistics of British popsong pronunciation". In: Peter Trudgill. On Dialect - Social and Geographical Perspectives. Oxford: Blackwell. 141-160.

Wells, J.C. 1982. Accents of English 1 - An Introduction. Cambridge: CUP.

Wells, J.C. 2010. Standard lexical sets. http://www.phon.ucl.ac.uk/home/wells/stanlexsets.htm. Accessed: 19 February 2012.

\section{Discography}

E.T. Mensah and his Tempos Band. 1950s. "Awirehow”. Decca West Africa.

E.T. Mensah and his Tempos Band. 1950s. "Day by Day". Decca West Africa.

E.T. Mensah and his Tempos Band. 1950s. "Don't Mind Your Wife". Decca West Africa.

E.T. Mensah and his Tempos Band. 1950s. "I Want to be Happy". Decca West Africa.

E.T. Mensah and his Tempos Band. 1950s. "Inflation Calypso" Decca West Africa.

E.T. Mensah and his Tempos Band. 1950s. "Sunday Mirror". Decca West Africa.

E.T. Mensah and his Tempos Band. 1950s. "Tea Samba". Decca West Africa.

Note on the discography: RetroAfric, London, offers reissues of E.T. Mensah's most famous recordings. 